\title{
Current State of Multidisciplinary Treatment in Cholangiocarcinoma
}

\author{
Najib Ben Khaled ${ }^{\mathrm{a}}$ Sven Jacob ${ }^{\mathrm{b}}$ Daniel Rössler ${ }^{\mathrm{a}}$ Florian Bösch $^{\mathrm{b}}$ \\ Enrico N. De Toni ${ }^{a}$ Jens Werner ${ }^{b}$ Jens Ricke ${ }^{c}$ Julia Mayerle ${ }^{a}$ \\ Max Seidensticker ${ }^{c}$ Christian Schulz ${ }^{a}$ Matthias P. Fabritius ${ }^{c}$
}

${ }^{a}$ Department of Medicine II, University Hospital, LMU Munich, Munich, Germany; ${ }^{\text {bDepartment }}$ of General-, Visceraland Transplantation-Surgery, University Hospital, LMU Munich, Munich, Germany; 'Department of Radiology,

University Hospital, LMU Munich, Munich, Germany

\section{Keywords}

Cholangiocarcinoma $\cdot$ Molecular profiling $\cdot$ Multidisciplinary treatment $\cdot$ Targeted therapy $\cdot$ Immunotherapy

\section{Abstract}

Background: Cholangiocarcinoma (CCA) is a highly aggressive malignancy, and its incidence seems to be increasing over the last years. Given the high rate of irresectability at the time of initial diagnosis, new treatment approaches are important to achieve better patient outcomes. Our review provides an overview of current multimodal therapy options across different specialties of gastroenterology/oncology, surgery, and interventional radiology. Summary: CCA is subdivided into clinically and molecularly distinct phenotypes. Surgical treatment currently is the only potentially curative therapy, but unfortunately, the majority of all patients are not eligible for resection at the time of initial diagnosis due to anatomic location, inadequate hepatic reserve, metastatic disease, or limiting comorbidities. However, multimodal treatment options are available to prolong survival, relieve symptoms, and maintain life quality. Key Messages: The treatment of CCA is complex and requires close interdisciplinary collaboration and individualized treatment planning to ensure optimal patient care at specialized centers. Molecular profiling of patients and inclusion into clinical trials is highly recommended.

(c) 2021 S. Karger AG, Basel

\section{Introduction}

Cholangiocarcinoma (CCA) is a highly aggressive, heterogenous malignancy originating from the epithelium of the biliary tract. CCA is considered a relatively rare cancer accounting for $<1 \%$ of all human cancers and the second most common primary liver cancer after hepatocellular carcinoma [1]. A varying distribution of risk factors and genetic susceptibility results in a high variability in CCA incidence [2]. While in the USA and Europe 1.63.4 cases per 100.000 inhabitants occur [3], South East Asia reports up to fiftyfold higher incidence rates, mainly due to endemic liver fluke infections (i.e., Clonorchis sinensis or Opisthorchis viverrini) [4]. CCA is slightly more common in men with a median age of onset between 60 and 70 years [5]. Most cases of CCA are sporadic. However, well-known risk factors were identified and are largely based on chronic biliary obstruction (e.g., due to

karger@karger.com www.karger.com/ddi

(c) 2021 S. Karger AG, Base

Karger"
Correspondence to:

Najib Ben Khaled, najib.benkhaled@med.uni-muenchen.de Matthias P. Fabritius, matthias.fabritius@med.uni-muenchen.de 
Fig. 1. Classifications of CCA. CCA arise from the epithelium of the biliary ducts within healthy or diseased liver parenchyma (e.g., cirrhosis, PSC, and chronic viral hepatitis). CCA are anatomically subclassified into CCA, pCCA, and distal CCA (dCCA). pCCA and dCCA are collectively referred to as extrahepatic CCA (eCCA). Intrahepatic CCA most typically shows mass-forming growth but can also present as periductal-infiltrating or intraductalgrowing tumor. Perihilar CCA are subdivided according to the Bismuth-Corlette classification and can grow in the common hepatic duct below the confluence (type I), reach the hepatic duct confluence (type II), involve common hepatic duct and the right (type IIIa) or left (type IIIb) hepatic duct or both right and left hepatic duct up to segmental infiltration (type IV, not shown). dCCA arise distal from the insertion of the cystic duct in the common bile duct. CCA, cholangiocarcinoma; iCCA, intrahepatic cholangiocarcinoma; pCCA, perihilar CCA; dCCA, distal CCA.

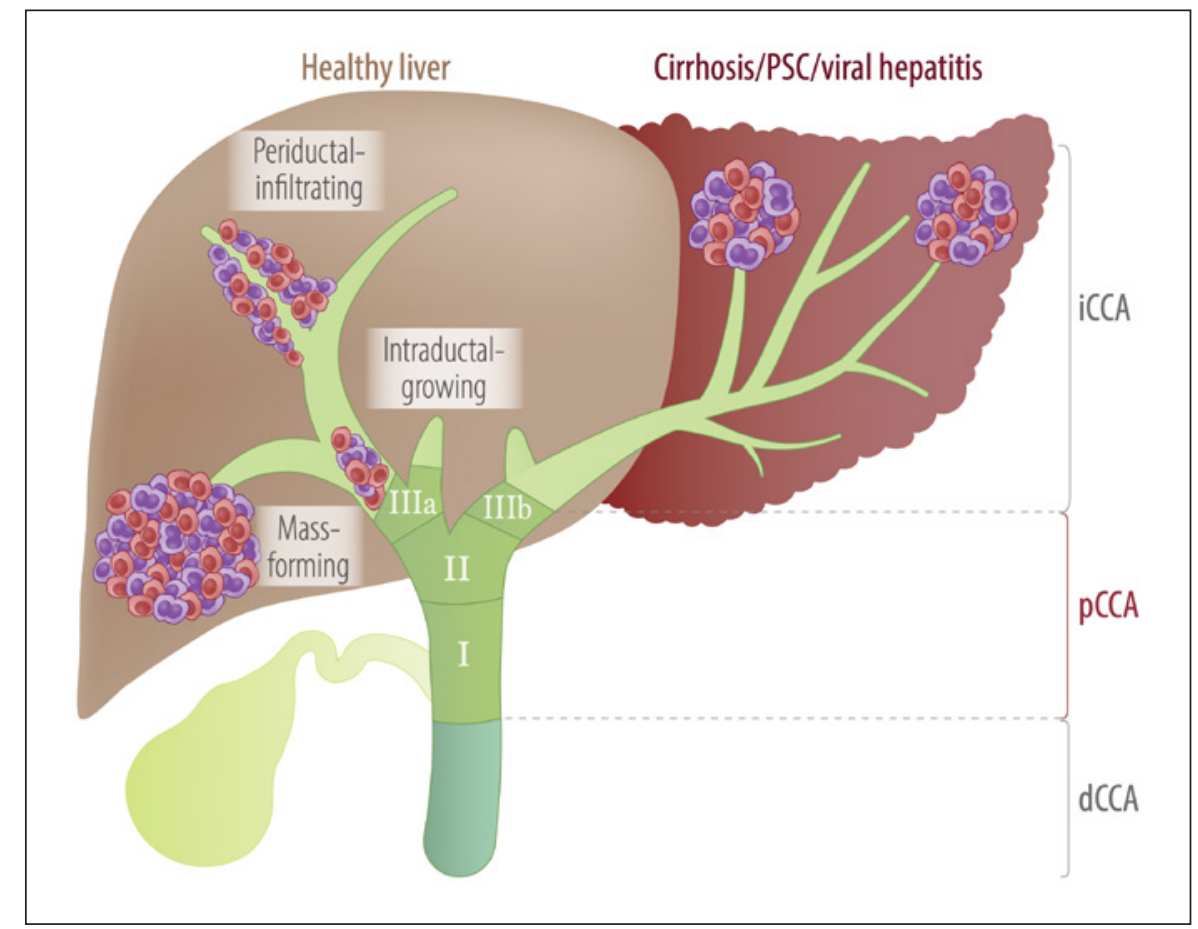

primary sclerosing cholangitis, gall stones, and biliary cysts), inflammation and lifestyle aspects $[6,7]$. Liver fluke infections, chronic viral hepatitis, nonalcoholic fatty liver disease, and cirrhosis are accompanied by prolonged inflammation of the bile ducts and thereby predispose to CCA development [8-10]. Furthermore, lifestyle aspects such as cigarette smoking, alcohol drinking, and obesity as well as type 2 diabetes and hypertension are associated with increased CCA risk [11, 12].

Anatomically and clinically, CCA is divided into 3 subgroups (Fig. 1) [13]:

1. Intrahepatic CCA (iCCA) arising from the segmental branches of the bile ducts.

2. Perihilar CCA (pCCA), historically called "Klatskin tumors," involving the right, left, and/or main hepatic duct as further subclassified by Bismuth-Corlette based on the ductal extent $[14,15]$.

3. Distal CCA (dCCA) growing in the common bile duct distal from the insertion of the cystic duct.

iCCA accounts for $5-10 \%$ of biliary tract cancers [13, 16]. However, iCCA incidence and mortality increased globally in the last decade probably due to a rise in major risk factors (viral hepatitis, obesity) and improvements in diagnosis which render misclassification of iCCA as cancer of unknown primary in the liver less common [1]. pCCA and dCCA constitute the majority of tumors (60$70 \%$ and $20-30 \%$, respectively), but their incidence tends to decline [17-19]. However, reports on the epidemiology of CCA should be valued with caution due to the changing nomenclature of the International Classification of Diseases (ICD) editions [18, 20]. Based on its growth pattern, CCA can also be categorized into the mass-forming type appearing as nodular lesions in the liver parenchyma, the periductal-infiltrating type growing along the biliary tree and the rare intraductal-growing type $[21,22]$. The anatomical localization of the different subtypes determines their clinical appearance. iCCA is frequently asymptomatic in earlier disease stages and only apparent as incidental finding on imaging or in advanced stages with clinical symptoms such as abdominal pain, weight loss, nausea, and jaundice $[13,23,24]$. pCCA and dCCA typically present with jaundice due to obstruction of biliary tracts in $90 \%$ of cases, occasionally complicated by cholangitis [13]. 70\% of CCA are diagnosed in advanced disease stages as defined by tumor invasion into the peritoneum and adjacent organs or extrahepatic spread [25]. The diagnosis of CCA is based on multimodality imaging such as computed tomography and magnetic resonance imaging. Because no specific radiological pattern is established for CCA, confirmatory histology from percutaneous/cholangioscopy-guided biopsy or endoscopic retrograde cholangiopancreatography (ERCP) is mandatory. 


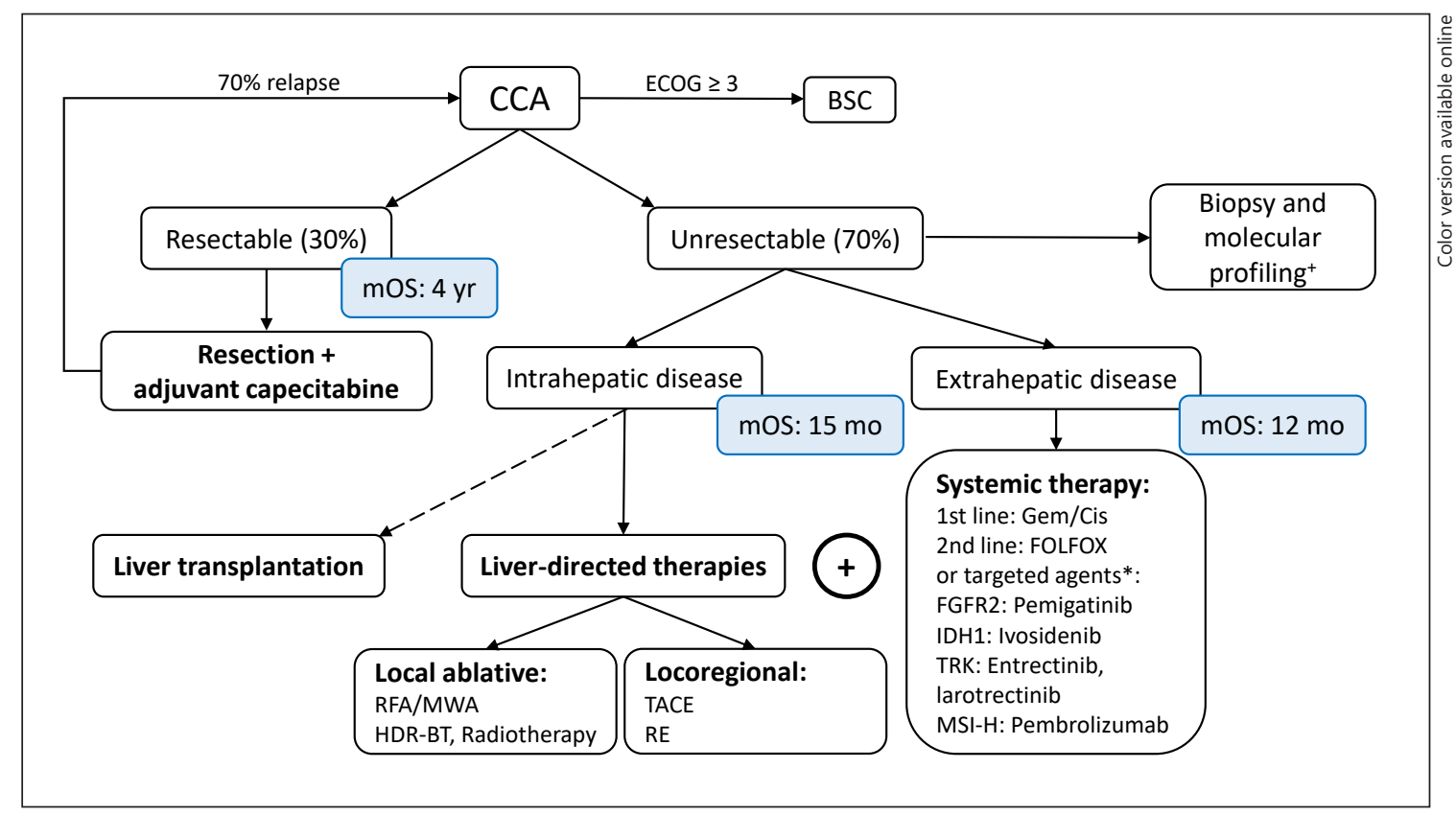

Fig. 2. Treatment flowchart for patients with CCA. BSC, best supportive care; ECOG, Eastern Cooperative Oncology Group Performance Status; FOLFOX, folinic acid, 5-fluorouracil and oxaliplatin; Gem/Cis, gemcitabine and cisplatin; HDR-BT, highdose-rate brachytherapy; mo, months; mOS, median overall survival; MWA, microwave ablation; $\mathrm{RE}$, yttrium-90 radioembolization; RFA, radiofrequency ablation; TACE, transarterial

\section{Treatment}

\section{Surgical Resection and Liver Transplantation}

Surgical resection is the only potential curative therapeutic approach in CCA [26]. The main objectives of surgery are tumor-free resection margins (R0), locoregional lymphadenectomy, and a sufficient future liver remnant (FLR). However, the majority of patients present with late-stage disease determining palliative treatment (Fig. 2).

The therapeutic strategy varies distinctly between iCCA, pCCA, and dCCA depending on the tumor location along the biliary tract. Thus, a precise preoperative diagnostic workup is highly demanded. Required diagnostic modalities include a CT scan with an arterial and a venous phase, a MR scan with liver-specific contrast agents and for pCCA and dCCA an ERCP. If preoperative biliary drainage is necessary, particularly the FLR has to be drained. Biliary drainage aims to increase possible FLR hypertrophy and reduce postoperative morbidity and mortality [27-29]. In the case of pCCA or dCCA, a biliary drainage should not be inserted before the diagnosis has chemoembolization; yr, years; CCA, cholangiocarcinoma. *Pemigatinib, entrectinib, larotrectinib, ivosidenib and pembrolizumab are approved by the FDA for treatment of patients with the respective genetic markers. ${ }^{+}$Biopsy and molecular profiling are recommended by the NCCN in patients with unresectable CCA, after liver transplantation has been ruled out as therapeutic option.

been secured since local inflammation might hinder the diagnosis [30]. However, the preferred drainage technique is still a matter of debate internationally. A multicenter, randomized controlled trial, comparing endoscopic versus percutaneous biliary drainage, had to be prematurely terminated due to increased mortality rates in the percutaneous transhepatic biliary drainage group [31]. Nonetheless, the percutaneous approach, which requires a high expertise and might lead to bleeding, has advantages as well (lower rates of infections and recurrent obstructions) [30, 32, 33]. The endoscopic insertion of a stent or a naso-biliary drainage, in turn, is associated with lower rates of bleeding, but with higher rates of infectious complications, such as cholangitis, pancreatitis, or surgical side infections [31,34]. An internal drainage increases patient comfort compared to either a naso-biliary or a percutaneous drainage.

Among surgically treated CCA, $10 \%$ are intrahepatic [35]. These tumors are often multifocal; thus, MR imaging is essential to detect (micro-)metastases. An imagingbased volumetric approximation of the FLR or additional liver function tests $[36,37]$ helps to avoid post-hepatec- 
tomy liver failure. If an insufficient FLR is expected, hypertrophy has to be achieved. To attain hypertrophy of the FLR a 2-step approach, including either portal vein embolization (PVE), in situ split (ALPPS), portal vein ligation (PVL), or interventional approaches, has to be evaluated on an individual basis [38-41]. Although the rates of FLR hypertrophy are similar between PVE and PVL, interventional procedures are preferred to induce hypertrophy of the FLR because they are less invasive [42]. In recent years, the effect of PVE has been evaluated in healthy livers as well as in pathologic livers, such as fibrosis or cirrhosis. Induction of hypertrophy is usually tested after 4-6 weeks and a hypertrophy of approximately $40 \%$ is expected in healthy livers [42, 43]. A further development of PVE is liver venous deprivation technique. This approach combines a PVE with the interventional occlusion of the right hepatic vein. It seems that this new technique achieves comparable results regarding time and hypertrophy compared to the "Associating Liver Partition and Portal vein Ligation for Staged hepatectomy" (ALPPS) procedure $[44,45]$. Furthermore, radioembolization, another interventional approach, combines the induction of hypertrophy of the FLR with a direct treatment of the hepatic tumor burden. Thus, this approach might prevent patients from not being considered for surgery due to hepatic tumor progression [40, 46, 47].

Resection of pCCA is guided by the Bismuth-Corlette [14] classification (Fig. 1). Due to the close proximity of the main bile duct, the portal vein and the hepatic artery, CT imaging, including arterial and venous phases, is crucial to assess vascular involvement. MRI and MRCP are most suitable to detect the main tumor. In case of intrahepatic cholestasis or cholangitis due to tumor obstruction, preoperative ERCP or percutaneous transhepatic cholangiography drainage might be necessary to reduce pressure in the FLR and decrease postoperative complication rates [48]. In cases of type I pCCA, the resection might be limited to the bile duct confluence [35]. However, also type I tumors often require an (extended) hemihepatectomy including the caudate lobe. Since the left main bile duct is longer than the right main bile duct, commonly a right-sided liver resection is performed. This approach leads to a greater chance of achieving tumorfree resection margins and facilitates the complete removal of the tumor mass preventing accidental tumor opening (no-touch technique). The same operative strategy might be feasible for type II and IIIa pCCA. A partial resection of the portal vein might additionally be necessary [49]. On the other hand, type IIIb pCCA requires a left-sided hemihepatectomy. From a surgical point of view, this scenario is probably the most challenging because the bile duct reconstruction includes 2-4 segmental branches and the resection of the caudate lobe. Second, an appropriate venous drainage of the remaining part of the right lobe has to be ensured while obligatorily resecting the middle liver vein. However, even in highly specialized centers, morbidity and mortality are high. Postoperative liver failure is thereby a feared complication [50]. Patients with CCA undergoing major resections have the highest complication rates as compared to other liver malignancies, but specialized centers feature with significantly lower complication rates $[51,52]$.

Liver transplantation might be considered in very few selected cases of iCCA and pCCA. The evidence for liver transplantation is weak and based on few case series, mostly retrospective [53-56]. A retrospective, multicenter study by 12 US transplantation centers published convincing data for selection criteria and neoadjuvant therapy of pCCA patients [55]. However, transplantation should only be done as part of clinical studies and if complete resection is not possible either due to inclusion of the distal hepatic artery or lack of bile duct remnants for anastomoses. Moreover, it seems that tumor biology is a more robust factor regarding eligibility for transplantation than tumor size. Thus, stable disease of at least 6 months is required prior liver transplantation [53]. Eligibility criteria are strict and extrahepatic tumor masses after neoadjuvant radio-chemotherapy have to be ruled out [57].

Surgery for dCCA commonly requires a pancreaticoduodenectomy and the main challenge is to attain tumorfree resection margins at the proximal bile duct. Extended multivisceral resections, including liver or colon, are only feasible in highly selected patients [58].

\section{Adjuvant and Neoadjuvant Therapy}

Curative resection aims at long-term disease-free survival. Due to the frequent relapse of CCA after surgery, there is an urgent need for effective adjuvant treatment. CCA relapse after curative surgery occurs globally in around $67-73 \%$ of patients with a median time to recurrence of 11-14 months [59-61] (Fig. 2). Unfortunately, only a small proportion of patients are amenable to repeated resection with curative intent after recurrence [61, 62]. The Bile Duct Cancer Adjuvant Trial and the PRODIGE-12-ACCORD-18 study failed to show a benefit for adjuvant gemcitabine and combination therapy with gemcitabine and oxaliplatin, respectively $[63,64]$. In the BILCAP trial, adjuvant capecitabine significantly prolonged disease-free survival across all biliary cancer subtypes, while no significance in overall survival (OS) was 
observed in the intention to treat population (51 vs. 36 months; $p=0.097)$. However, as data from a per-protocol analysis (51 vs. 36 months; $p=0.028$ ) demonstrated a significant survival benefit adjuvant capecitabine is now considered standard of care $[65,66]$.

Results of 2 phase III trials are highly anticipated. The ongoing ACTICCA-1 study, investigating the role of gemcitabine and cisplatin, has been delayed in completion due to protocol adaptions to account for the change in clinical standard from observation to capecitabine treatment [67]. The ASCOT trial evaluating the effect of adjuvant $\mathrm{S} 1$, a modulated oral fluoropyrimidine prodrug, has finished recruiting recently; results have not been published to date [68]. Among a growing number of phase II trials, one of the most notable is the SWOG-0809 trial, which reported a promising 2-year survival rate of $65 \%$ after adjuvant radiotherapy in combination with gemcitabine and capecitabine in patients with eCCA or gallbladder cancer presenting with high-risk features [69]. Most recent approaches explore combination therapies with capecitabine including radiotherapy, tyrosine kinase inhibitors, and immune checkpoint inhibitors (CPI). It remains unclear if the promising results for molecular targeted therapies described below can be transferred into the adjuvant setting as well.

At the moment, there is no role for neoadjuvant treatment for CCA. Some phase I and II trials have been performed, enrolling low patient numbers. The GAIN trial investigating the efficacy of neoadjuvant and adjuvant gemcitabine/cisplatin is the first randomized clinical trial (RCT) in resectable biliary tract cancer [70]. Results are expected by 2024 .

\section{Locoregional Treatment}

For patients with unresectable iCCA as well as intrahepatic CCA metastases, various locoregional therapy options exist in addition to systemic therapy [71]. Up to now the evidence is not strong with most of the conclusions drawn from single-center retrospective analyses with small sample sizes treated in the salvage situation. However, the results are promising and suggest a survival benefit in the treatment of unresectable CCA in selected patients, even in an advanced stage with extrahepatic disease. Moreover, leading goals of palliative locoregional therapy are to control local tumor growth, relieve symptoms, and improve and maintain quality of life. In a curative setting, preoperative PVE as an interventional procedure enables patients with too little standardized FLR to achieve resectability by inducing hypertrophy of the healthy liver.

Treatment in Cholangiocarcinoma
Local Ablative Techniques

Local ablative procedures such as radiofrequency ablation (RFA), microwave ablation (MWA), or interstitial high-dose-rate brachytherapy (HDR-BT) can be used in patients with circumscribed single or few intrahepatic lesions. As ablative techniques, their intention is complete and durable local tumor destruction. Nevertheless, there are limitations in the use of thermal methods (RFA and MWA) depending on the size and location of the tumors. Adjacent large blood vessels cause cooling effects that may counteract adequate heat generation and hinder complete ablation of the tumor [72]. Peripheral lesions adjacent to hollow organs, as well as centrally located lesions (near or comprising the major bile ducts), are only partially amenable to thermal-based ablation due to associated complications. Regarding size limitation, the German Society for Interventional Radiology and Minimally Invasive Therapy (DEGIR) recommends a maximum tumor diameter of $3.5 \mathrm{~cm}$ for multifocal metastasis and $5 \mathrm{~cm}$ for a single focus to ensure safe ablation. Considering that iCCA is usually diagnosed in an advanced stage, these restrictions usually preclude the application of thermal methods and they therefore play a minor role in the therapy regime. However, small tumors as first diagnosis or as recurrence in the remnant liver after initial surgery in patients not willing or eligible for (re)resection, could be candidates for thermal ablation. For example, a small single-center study with 13 patients described a local control rate of $88 \%$ and a median OS of 38.5 months in selected patients with small lesions $(<5 \mathrm{~cm})$ after thermal ablation [73].

In contrast, image-guided interstitial brachytherapy (HDR-BT, a catheter-based radiotherapy) is largely independent of tumor location and tumor size, and thus can be used for larger tumors, as well as for lesions in proximity to hilar structures. In brief, liver tumors are treated with a high-dose rate iridium-192 source in afterloading technique after percutaneous positioning of brachytherapy catheters under CT or MRI control [74-78]. The prescribed minimum dose for the clinical target volume is 20 Gy $[79,80]$. Specifically, in patients where RFA or MWA is not feasible, HDR-BT is a useful option in selected patients. Schnapauff et al. [77] evaluated outcomes after repeated HDR-BT in 15 therapy-naïve patients (27 sessions) with unresectable iCCA who suffered from limited hepatic disease only ( $<5$ lesions, size up to $12 \mathrm{~cm}$ ), revealing a median survival of 14 months after HDR-BT and 21 months after primary diagnosis. Further on, effective treatment with HDR-BT of iCCA recurrences after initial resection was shown with a 1-year and 5-year survival of 
$77.1 \%$ and $51.4 \%$, respectively, in a small case series of 10 patients [81]. Data on combined local treatment and chemotherapy is not published yet. However, there are recruiting trials evaluating the efficacy of HDR-BT in combination with gemcitabine and cisplatin in irresectable iCCA patients (CHOICE trial, DRKS00007161).

\section{Locoregional Therapies}

For patients with multifocal or diffuse hepatic involvement, locoregional therapeutic procedures, such as transarterial chemoembolization (conventional TACE or TACE with drug eluting beads), or yttrium-90-radioembolization (RE) are available if liver function is sufficient [82-84]. Several retrospective cohorts were published analyzing the outcome after TACE in iCCA patients. OS ranged from 10 to 16.3 months, reported objective response rate (RR) usually did not exceed $25 \%$ [83, 85-92]. Comparing objective response, OS, and tolerability, RE seems to be superior to TACE [93]. Multiple retrospective studies analyzed outcome after RE in unresectable iCCA patients who were treated in different settings: therapynaïve, as intensification during chemotherapy, and in chemotherapy-refractory stage [71, 82, 84, 94-102]. A meta-analysis of 298 patients reported a pooled median OS of 14.3 months after RE [103], indicating superior survival compared to chemotherapy with gemcitabine and cisplatin alone (11.7 months) [104]. However, studies contained mixed populations and a selection bias needs to be assumed. Furthermore, a recent post hoc analysis of prospective trials showed that patients diagnosed with advanced iCCA have a better OS (16.7 months) compared with other biliary tract cancers after first-line chemotherapy with gemcitabine and cisplatin, which indicates that survival data from Valle et al. [105] are underestimated with respect to this patient subgroup that is predominantly accessible for radiological interventional therapies. These results were confirmed in a prospective trial combing RE and gemcitabine/cisplatin, with a median progression-free survival (PFS) of $30 \%$ at 24 months, and $22 \%$ of patients downstaged to resection. Out of these, median relapse-free-survival was not reached at 46 months [106]. Results have been used to prepare an upcoming phase 3 study design (NCT02807181).

Further studies which included the combination of RE and chemotherapy with gemcitabine and cisplatin indicated superior efficacy of combined treatment compared with RE alone [82], others suggested similar efficacy [107]. Importantly no study suggests increased toxicity when the treatments were combined.
The fact that patients usually present for such procedures only at an advanced and often chemotherapy-refractory stage of disease is important for the interpretation of the published data. Considering this, survival rates with a survival time of 10-18 months after locoregional therapy are relatively high [108]. The efficacy of RE and TACE is further underlined by reports of secondary resectability after treatment (although in rare and individual cases only) [109] as well as high local RRs, which are probably a better descriptor of efficacy here, as many patients receive further systemic therapies before and often after local treatment, and thus survival results reflect combinations of different therapies, or different therapy timing. Interestingly, many studies observed that the presence of limited extrahepatic manifestations (usually lymph nodes, bone, and lung) had no impact on survival indicating that local tumor control and concomitant maintenance of liver function is essential for outcome $[71,93]$.

Altogether, studies on interventional radiologic therapies for iCCA show encouraging results in selected patients regarding OS, so that these treatment options are gaining increasing attention, also considering the limited options for systemic therapy. Such therapeutic approaches might be used in individualized treatment concepts, but data need validation in larger prospective trials. Encouragingly, the efficacy of RE as combination therapy with gemcitabine/cisplatin versus gemcitabine/cisplatin alone in the first-line setting is currently being investigated in a large prospective multicenter study (NCT02807181).

\section{Endoscopic Therapies}

In addition to the supportive role of endoscopy to treat biliary tract or GI-tract obstruction and cholangitis in CCA, endoscopic intraluminal ablative approaches such as photodynamic therapy (PDT) or RFA have also been investigated. Several retrospective studies, 2 small RCTs and a meta-analysis demonstrated a promising benefit for PDT in patients with unresectable biliary tract cancer [110-112], while a recent large randomized study in patients with locally advanced or metastatic disease showed an inferior survival for patients treated with PDT [113]. RFA is another intraductal ablative procedure with promising data in clinical studies. Recent data from a systematic meta-analysis [114] and 2 RCTs $[115,116]$ comparing biliary RFA and stenting versus stenting alone demonstrated a survival benefit and manageable safety profile of intraductal RFA. Based on the limited data, both approaches can be considered as palliative treatment op- 
tions in patients with unresectable perihilar or dCCA and cholestasis, although PDT is not widely used. Clinical studies directly comparing the efficacy of PDT and RFA are lacking. Furthermore, a possible role of intraluminal approaches in combination with systemic chemotherapy remains to be elucidated. Yang and colleagues [117] recently reported a RCT showing favorable efficacy and safety for RFA combined with chemotherapy with the agent $\mathrm{S} 1$ as combined to RFA alone for unresectable eCCA. An ongoing RCT examines the benefit of combined PDT and systemic chemotherapy with gemcitabine/ cisplatin (NCT04099888).

\section{Systemic Treatment for Advanced CCA}

Systemic treatment is the mainstay of therapy in patients with unresectable CCA. The aim of systemic therapy is to prolong patient's survival and to reduce cancerassociated symptoms while maintaining a sufficient quality of life and minimize treatment-associated toxicity. Patients with bad performance status, as defined by an Eastern Cooperative Oncology Group (ECOG) performance status $>2$ or impaired liver function disqualify for systemic treatment.

\section{Cytotoxic Chemotherapy}

More than a decade after the publication of the ABC02 trial and the confirmatory Japanese BT22 study [118, 119], Gemcitabine/cisplatin remains the globally accepted standard of care in the first-line treatment of advanced CCA. Gemcitabine/cisplatin markedly improved the primary endpoint of OS as compared to gemcitabine alone, with a median OS of 11.7 months versus 8.1 months $(p<$ 0.001 ), a median PFS of 8.0 months versus 5.0 months $(p<0.001)$, and a RR of $26.1 \%$ versus $15.5 \%$ [119]. Gemcitabine/cisplatin reduces the rate of cholangitis and liver failure [120]. Upon progression on first-line chemotherapy, the ABC-06 trial established mFOLFOX (modified FOLFOX, consisting of folinic acid, 5-fluorouracil, and oxaliplatin) as second-line treatment based on a small, but statistically significant difference in median OS with 6.2 months for mFOLFOX versus 5.3 months with active symptom control $(p=0.031)$ and a clinical meaningful benefit in 6- and 12-months survival rates $(50.6 \%$ vs. $35.5 \%, 25.9 \%$ vs. $11.4 \%$ ) [121]. Median PFS was 4.0 months and RR 5\%. The benefit of mFOLFOX was consistent among all subgroups and even in patients resistant or refractory to platinum in the first line.

Newer studies focus on triple agent combinations to further increase antitumor activity. The addition of nabpaclitaxel to gemcitabine/cisplatin in a phase II trial dem- onstrated an impressing median OS of 19.2 months, a PFS of 11.8 months, and an overall RR (ORR) of $45 \%$ with some patients downstaged to resectability [122]. Based on these findings, a phase III trial is comparing the combination of nab-paclitaxel/gemcitabine/cisplatin to the standard of care gemcitabine/cisplatin (NCT03768414). A Japanese trial showed a significant improvement of survival and PFS with the agent $\mathrm{S} 1$ and gemcitabine/cisplatin as compared to gemcitabine/cisplatin alone (OS 13.5 months vs. 12.6 months; $p=0.046$, PFS 7.4 months vs. 5.5 months; $p=0.0015)$. The first-in-class compound NUC1031 is a prodrug of gemcitabine and was developed to overcome major resistance mechanisms to gemcitabine [123]. Based on favorable results in the CCA cohort in a phase I basket trial, the combination of NUC-1031 and cisplatin in comparison to gemcitabine/cisplatin is currentlybeinginvestigatedinaphaseIIItrial(NCT04163900). FOLFIRINOX (folinic acid, 5-fluorouracil, irinotecan, and oxaliplatin), highly active in patients with metastatic pancreatic cancer [124], failed to show a clinical benefit in biliary tract cancer in a French phase II/III trial [125].

\section{Molecularly Targeted Therapy}

CCA is a genetically complex tumor with a high number of mutations affecting various oncogenic pathways [126-129]. The current development of CCA therapy is an outstanding example of precision medicine, with nextgeneration sequencing approaches identifying actionable mutations across the different disease subtypes and circulating tumor DNA used to monitor treatment response and emergence of resistant clones as part of biomarkerbased clinical trials [130] (Table 1). More than $50 \%$ of patients with intrahepatic CCA show targetable mutations, as reviewed by Lamarca and colleagues [131]. Briefly, the most common involve fibroblast growth factor receptor 2 (FGFR2) gene fusions and isocitrate dehydrogenase (IDH) 1 and 2 mutations (each in around $20 \%$ of cases), less common B-raf kinase (BRAF) mutations, ERBB alterations, or tropomyosin receptor kinase (TRK) fusions $[129,132,133]$. In contrast, the molecular profile of eCCA shows similarity to pancreatic ductal adenocarcinoma with frequent mutations in KRAS, TP53, SMAD4, and ERBB family.

FGFR gene alterations have been identified as driver mutations in intrahepatic cholangiocarcinogenesis with FGFR2 gene fusions being the most prevalent and the most sensitive to FGFR inhibition [134]. Various reversible (infigratinib, pemigatinib, derazantinib, and erdafitinib) and irreversible (futibatinib) selective, oral FGFRinhibitors have been developed and investigated as 
Table 1. Targeted agents for treatment of advanced CCA

\begin{tabular}{|c|c|c|c|c|c|c|c|c|c|}
\hline $\begin{array}{l}\text { Biomarker/ } \\
\text { target }\end{array}$ & $\begin{array}{l}\text { Prevalence, } \\
\%\end{array}$ & Drugs & $\begin{array}{l}\text { Trial } \\
\text { phase }\end{array}$ & $\begin{array}{l}\text { Patients, } \\
n\end{array}$ & $\begin{array}{l}\text { ORR, } \\
\%\end{array}$ & $\begin{array}{l}\text { PFS, } \\
\text { mo }\end{array}$ & $\begin{array}{l}\text { OS, } \\
\text { mo }\end{array}$ & Side effects (pooled) & $\begin{array}{l}\text { Referen- } \\
\text { ces }\end{array}$ \\
\hline \multirow[t]{4}{*}{ FGFR } & \multirow{4}{*}{$\begin{array}{l}\text { iCCA: } 20^{+} \\
\text {eCCA: } 3^{+}\end{array}$} & Infigratinib & 2 & $108\left(108^{\circ}\right)$ & 23.1 & 7.3 & 12.5 & \multirow{4}{*}{$\begin{array}{l}\text { Hyperphosphatemia, fatigue, stomatitis, } \\
\text { diarrhea, alopecia, eye toxicity }\end{array}$} & {$[115,120]$} \\
\hline & & Derazantinib & $1 / 2$ & $29\left(29^{\circ}\right)$ & 20.7 & 5.7 & NR & & [118] \\
\hline & & Erdafitinib & $2 \mathrm{a}$ & $14\left(8^{\circ}\right)$ & 50.0 & 5.6 & NR & & [119] \\
\hline & & Futibatinib & 2 & $103\left(103^{\circ}\right)$ & 37.3 & 7.2 & NR & & {$[121,122]$} \\
\hline \multirow[t]{2}{*}{ TRK } & \multirow[t]{2}{*}{$4^{+}$} & Entrectinib & 2 & $54\left(1^{\#}\right)$ & 57 & 11.2 & 21 & \multirow{2}{*}{$\begin{array}{l}\text { Weight gain, transaminitis, anemia, } \\
\text { dizziness, fatigue }\end{array}$} & [134] \\
\hline & & Larotrectinib & 2 & $55\left(2^{\#}\right)$ & 75 & NR & NR & & [133] \\
\hline $\mathrm{BRAF}^{\mathrm{V} 600 \mathrm{E}}$ & $3^{+}$ & $\begin{array}{l}\text { Dabrafenib/ } \\
\text { trametinib }\end{array}$ & 2 & 43 & 47 & NR & NR & $\begin{array}{l}\text { Increased GGT, pyrexia, nausea, vomiting, } \\
\text { diarrhea }\end{array}$ & [135] \\
\hline
\end{tabular}

BRAFV600E, B-raf kinase V600E mutation; FGFR2, fibroblast growth factor receptor 2 alterations; GGT, gamma-glutamyl transferase; IDH1, isocitrate dehydrogenase 1; irAEs, immune-related adverse events; mo, months; $\mathrm{MSI}-\mathrm{H}$, high microsatellite instability; NR, not reported; ORR, objective response rate; OS, overall survival;PFS, progression-freesurvival;TRK, tropomyosin receptorkinasefusions;CCA, cholangiocarcinoma;iCCA, intrahepaticcholangiocarcinoma. ${ }^{+}$Adapted from [131]. * Pemigatinib results for cohort 1, patients with FGFR2 gene alterations. ${ }^{\circ}$ Number of patients with FGFR2 fusions/rearrangements. \# Number of patients with CCA in the study population of patients with TRK positive cancers.

monotherapy in phase 2 trials in pretreated patients with advanced iCCA (Table 1). Outcomes in patients with FGFR2 gene fusions were impressive: ORR ranges from $21 \%$ to $50 \%$ with high disease control rates of $82-84 \%$, median PFS of 5.9-7.3 months, and OS of 12.5-21.1 months [135-139]. However, in patients without FGFR alterations, these agents did not show activity. Side effects are similar and include hyperphosphatemia due to inhibition of FGF-mediated phosphate elimination in the kidneys, fatigue, gastrointestinal (stomatitis and diarrhea); skin (alopecia and nail changes); and eye (dry eye, conjunctivitis, and vision changes) toxicity. With pemigatinib the first FGFR-inhibitor has been approved by the FDA for the treatment of patients with advanced iCCA and FGFR2 gene fusions in April 2020 [137], infigratinib is currently being reviewed by the FDA for the same indication [140]. Three randomized phase III trials evaluate the efficacy of infigratinib (NCT03773302), pemigatinib (NCT03656536), and futibatinib (NCT04093362) against gemcitabine/cisplatin in the first-line treatment of advanced iCCA with FGFR2 gene alterations.

Mutations in IDH $1 / 2$ enzymes lead to the production of the oncometabolite 2-hydroxyglutarate stimulating DNA-hypermethylation leading to CCA formation and progression [133]. The phase III ClarIDHy study ran- domized pretreated patients with advanced, IDH1 mutant CCA to receive either the IDH1 inhibitor ivosidenib or placebo with primary endpoint PFS and the possibility for cross-over after progression (Table 1). Ivosidenib improved the primary endpoint with a median PFS of 2.7 months versus 1.4 months ( $p<0.0001)$, but no statistically significant OS benefit (10.3 months vs. 7.5 months, $p=0.093)[141,142]$. Treatment was well tolerated with mainly GI-side effects (nausea, diarrhea, and abdominal pain) and fatigue. FDA approval was granted recently [143].

Targetable ERBB-2/HER2 overexpression or amplification is observed in 20\% of eCCA and 5\% of iCCA [144]. Early clinical trials investigating the addition of cetuximab, panitumumab, or erlotinib to cytotoxic chemotherapy or monotherapy with lapatinib were disappointing [145-149]. New ongoing studies focus on the evaluation of antibody-drug conjugates and bispecific antibodies targeting HER2 with promising activity in the early clinical phase $[150,151]$.

$B R A F^{\mathrm{V} 600 \mathrm{E}}$ mutations and TRK fusions are rare events in CCA with a frequency of around 3-5\% each $[152,153]$. However, phase II basket trials of dabrafenib plus trametinib in $B R A F^{\mathrm{V} 600 \mathrm{E}}$ mutated cancers and larotrectinib or entrectinib in TRK-fusion positive cancers showed high RRs (47\% for dabrafenib/trametinib, 57\% for entrec- 
tinib, and 75\% for larotrectinib) and durable responses (9 months for dabrafenib/trametinib, 10 months for entrectinib, not reached for larotrectinib) in the biliary tract cancer cohorts [153-155] (Table 1). Entrectinib and larotrectinib are FDA-approved for the treatment of TRK-fusion positive solid tumors.

Immunotherapy

CPI-based immunotherapy has marked a breakthrough in the treatment of a variety of malignancies [156]. CCA is not considered to be a highly immunogenic tumor characterized by a dense desmoplastic and immunosuppressive stroma [157], a low frequency of high microsatellite instability (MSI-H) of around $1-5 \%$ [158-160], and a low median tumor mutational burden [161]. Unsurprisingly, results of CPI monotherapy trials have been disappointing so far, except in the small subgroup of MSI-H patients (Table 1). Monotherapy with anti-PD-1 inhibitor pembrolizumab or nivolumab, as well as anti-PD-L1 inhibitor durvalumab was tested in early phase clinical trials in patients with advanced biliary tract cancer and progression upon standard chemotherapy. ORR was low from $3.4 \%$ to $13.0 \%$, OS was between 5.2 months and 8.1 months, regardless of PD-L1 expression status [162-164]. However, profound and durable responses upon pembrolizumab monotherapy could be observed in pretreated patients with MSI-H advanced CCA in a phase II trial with an ORR of $40.9 \%$ and OS of 24.3 months [165] (Table 1). Two trials investigated the role of double checkpoint inhibition with a combination of PD-1/PD-L1 and CTLA-4 blockade with nivolumab/ipilimumab or durvalumab/tremelimumab to unleash the antitumor immune response in CCA [164, 166]. Activity was slightly increased with an ORR of $11-$ $23 \%$ and an OS of 5.7-10.1 months, but at the expense of higher toxicity with $15-23 \%$ of patients experiencing relevant adverse events. Several other combination partners with the ability to modify the tumor microenvironment and sensitize CCA to CPI treatment are being investigated. The combination of gemcitabine/cisplatin and durvalumab with or without tremelimumab was investigated in a randomized phase II clinical trial in patients with therapy naïve advanced CCA. Outcomes were favorable with an ORR of $73 \%$ and OS between 18.1 and 20.7 months. Two randomized phase III clinical trials are currently assessing the role of combined PD-1/PD-L1 inhibition and gemcitabine/cisplatin in the first-line setting (TOPAZ-1: gemcitabine/cisplatin + durvalumab; NCT03875235, Keynote 966: gemcitabine/cisplatin + pembrolizumab; NCT04003636). Furthermore, the bi- functional fusion antibody bintrafusp alfa targeting PD$\mathrm{L} 1$ and TGF- $\beta$ in addition to gemcitabine/cisplatin is being investigated in a phase II/III trial (NCT04066491) in treatment-naïve patients with advanced biliary tract cancer. Other interesting studies with promising results in phase II single-arm studies and the need for investigation in a randomized controlled setting include the combination of pembrolizumab plus multi-kinase inhibitor lenvatinib $[167,168]$, or pembrolizumab plus granulocyte macrophage colony-stimulating factor [169]. Furthermore, CPI with local therapies such as radiotherapy (NCT03482102), RFA (NCT02821754), or SIRT (NCT04238637) as well as CPI plus PARP inhibitors (NCT03991832) are therapeutic strategies currently assessed in early phase trials. However, new combination regimens could always cause an over-proportionally strong toxicity, as reported by a combination regimen of durvalumab, tremelimumab, and paclitaxel in biliary tract cancer patients [170]. Sponsors and trial physicians should therefore pay special attention to safety signals and adverse events in trials of CPI-based combination regimens.

\section{Conclusion}

CCA is a rare and aggressive cancer divided in clinicopathologically and molecularly distinct subgroups. The treatment of CCA is complex. Interdisciplinary discussion and close cooperation between hepatobiliary and transplant surgery, interventional radiology, endoscopists, and oncologists are mandatory in the treatment of each CCA patient. Given a subset of targetable genetic alterations, molecular profiling for patients with unresectable CCA should be performed as part of the initial diagnostic workup. Advances in targeted therapies, new chemo- and immunotherapy regimens and combinations between systemic treatment and local interventions have the potential to revolutionize the clinical management of the disease and improve patients' outcomes. Treatment of patients in specialized centers with the possibility of inclusion into clinical trials is highly recommended.

\section{Conflict of Interest Statement}

N.B.K. has received reimbursement of meeting attendance fees and travel expenses from EISAI and lecture honoraria from Falk. All the other authors have no conflicts of interest to declare. 


\section{Funding Sources}

The authors did not receive any specific grants for this manuscript.

\section{Author Contributions}

All the authors contributed to the literature review and search, writing, formatting, and editing of the manuscript. N.B.K. and M.P.F. designed the figures, answered the questions of the peer reviewers' and replied to their comments with approval of all authors. All the authors approved the submitted manuscript.

\section{References}

1 Saha SK, Zhu AX, Fuchs CS, Brooks GA. Forty-year trends in cholangiocarcinoma incidence in the U.S.: intrahepatic disease on the rise. Oncologist. 2016;21(5):594-9.

2 Torre LA, Siegel RL, Ward EM, Jemal A. Global cancer incidence and mortality rates and trends: an update. Cancer Epidemiol Biomarkers Prev. 2016;25(1):16-27.

3 Khan SA, Tavolari S, Brandi G. Cholangiocarcinoma: epidemiology and risk factors. Liver Int. 2019;39 Suppl 1:19-31.

4 Kamsa-Ard S, Luvira V, Suwanrungruang K, Kamsa-Ard S, Luvira V, Santong C, et al. Cholangiocarcinoma trends, incidence, and relative survival in Khon Kaen, Thailand from 1989 through 2013: a population-based cancer registry study. J Epidemiol. 2019;29(5): 197-204.

5 Edge SB, Byrd DR, Carducci MA, Compton CC, Fritz A, Greene F. AJCC cancer staging manual. New York: Springer; 2010.

6 Clements O, Eliahoo J, Kim JU, Taylor-Robinson SD, Khan SA. Risk factors for intrahepatic and extrahepatic cholangiocarcinoma: a systematic review and meta-analysis. J Hepatol. 2020;72(1):95-103.

7 Cai H, Kong WT, Chen CB, Shi GM, Huang $\mathrm{C}$, Shen $\mathrm{YH}$, et al. Cholelithiasis and the risk of intrahepatic cholangiocarcinoma: a metaanalysis of observational studies. BMC Cancer. 2015;15:831.

8 Li M, Li J, Li P, Li H, Su T, Zhu R, et al. Hepatitis $B$ virus infection increases the risk of cholangiocarcinoma: a meta-analysis and systematic review. J Gastroenterol Hepatol. 2012;27(10):1561-8.

9 Wongjarupong N, Assavapongpaiboon B, Susantitaphong $\mathrm{P}$, Cheungpasitporn $\mathrm{W}$, Treeprasertsuk S, Rerknimitr R, et al. Non-alcoholic fatty liver disease as a risk factor for cholangiocarcinoma: a systematic review and meta-analysis. BMC Gastroenterol. 2017; 17(1):149.

10 Xia J, Jiang SC, Peng HJ. Association between liver fluke infection and hepatobiliary pathological changes: a systematic review and meta-analysis. PLoS One. 2015;10(7):e0132673.

11 Palmer WC, Patel T. Are common factors involved in the pathogenesis of primary liver cancers? A meta-analysis of risk factors for intrahepatic cholangiocarcinoma. J Hepatol. 2012;57(1):69-76.

12 Welzel TM, Graubard BI, Zeuzem S, El-Serag HB, Davila JA, McGlynn KA. Metabolic syndrome increases the risk of primary liver can- cer in the United States: a study in the SEERMedicare database. Hepatology. 2011;54(2): $463-71$.

13 Nakeeb A, Pitt HA, Sohn TA, Coleman J, Abrams RA, Piantadosi S, et al. Cholangiocarcinoma. A spectrum of intrahepatic, perihilar, and distal tumors. Ann Surg. 1996;224(4): 463-75.

14 Bismuth $\mathrm{H}$, Corlette MB. Intrahepatic cholangioenteric anastomosis in carcinoma of the hilus of the liver. Surg Gynecol Obstet. 1975; 140(2):170-8.

15 Klatskin G. Adenocarcinoma of the hepatic duct at its bifurcation within the porta hepatis. An unusual tumor with distinctive clinical and pathological features. Am J Med. 1965;38: 241-56.

16 DeOliveira ML, Cunningham SC, Cameron JL, Kamangar F, Winter JM, Lillemoe KD, et al. Cholangiocarcinoma: thirty-one-year experience with 564 patients at a single institution. Ann Surg. 2007;245(5):755.

17 Bertuccio P, Malvezzi M, Carioli G, Hashim D, Boffetta P, El-Serag HB, et al. Global trends in mortality from intrahepatic and extrahepatic cholangiocarcinoma. J Hepatol. 2019; 71(1):104-14.

18 Tyson GL, Ilyas JA, Duan Z, Green LK, Younes M, El-Serag HB, et al. Secular trends in the incidence of cholangiocarcinoma in the USA and the impact of misclassification. Dig Dis Sci. 2014;59(12):3103-10.

19 Khan SA, Taylor-Robinson SD, Toledano MB, Beck A, Elliott P, Thomas HC. Changing international trends in mortality rates for liver, biliary and pancreatic tumours. J Hepatol. 2002;37(6):806-13.

20 Khan SA, Emadossadaty S, Ladep NG, Thomas HC, Elliott P, Taylor-Robinson SD, et al. Rising trends in cholangiocarcinoma: is the ICD classification system misleading us? J Hepatol. 2012;56(4):848-54.

21 Nakanuma Y, Sato Y, Harada K, Sasaki M, Xu J, Ikeda H. Pathological classification of intrahepatic cholangiocarcinoma based on a new concept. World J Hepatol. 2010;2(12):41927.

22 Yamasaki S. Intrahepatic cholangiocarcinoma: macroscopic type and stage classification. J Hepatobiliary Pancreat Surg. 2003;10(4): 288-91.

23 Cha JM, Kim MH, Lee SK, Seo DW, Lee SS, Lee JH, et al. Clinicopathological review of 61 patients with early bile duct cancer. Clin Oncol. 2006;18(9):669-77.
24 Alvaro D, Bragazzi MC, Benedetti A, Fabris L, Fava G, Invernizzi $P$, et al. Cholangiocarcinoma in Italy: a national survey on clinical characteristics, diagnostic modalities and treatment. Results from the "cholangiocarcinoma" committee of the Italian Association for the study of liver disease. Dig Liver Dis. 2011; 43(1):60-5.

25 Shen WF, Zhong W, Xu F, Kan T, Geng L, Xie $\mathrm{F}$, et al. Clinicopathological and prognostic analysis of 429 patients with intrahepatic cholangiocarcinoma. World J Gastroenterol. 2009;15(47):5976-82.

26 Ito F, Cho CS, Rikkers LF, Weber SM. Hilar cholangiocarcinoma: current management. Ann Surg. 2009;250(2):210-8.

27 Rassam F, Roos E, van Lienden KP, van Hooft JE, Klümpen HJ, van Tienhoven G, et al. Modern work-up and extended resection in perihilar cholangiocarcinoma: the AMC experience. Langenbecks Arch Surg. 2018; 403(3):289-307.

28 Ratti F, Cipriani F, Fiorentini G, Hidalgo Salinas C, Catena M, Paganelli M, et al. Management of hilum infiltrating tumors of the liver: the impact of experience and standardization on outcome. Dig Liver Dis. 2019;51(1):13541.

29 Olthof PB, Wiggers JK, Groot Koerkamp B, Coelen RJ, Allen PJ, Besselink MG, et al. Postoperative liver failure risk score: identifying patients with resectable perihilar cholangiocarcinoma who can benefit from portal vein embolization. J Am Coll Surg. 2017;225(3): 387-94.

30 Dondossola D, Ghidini M, Grossi F, Rossi G, Foschi D. Practical review for diagnosis and clinical management of perihilar cholangiocarcinoma. World J Gastroenterol. 2020; 26(25):3542-61.

31 Coelen RJS, Roos E, Wiggers JK, Besselink MG, Buis CI, Busch ORC, et al. Endoscopic versus percutaneous biliary drainage in patients with resectable perihilar cholangiocarcinoma: a multicentre, randomised controlled trial. Lancet Gastroenterol Hepatol. 2018;3(10):681-90.

32 Tang Z, Yang Y, Meng W, Li X. Best option for preoperative biliary drainage in Klatskin tumor: a systematic review and meta-analysis. Medicine. 2017;96(43):e8372.

33 Takahashi $\mathrm{Y}$, Ito $\mathrm{H}$, Inoue $\mathrm{Y}$, Mise $\mathrm{Y}$, Ono $\mathrm{Y}$, Sato T, et al. Preoperative biliary drainage for patients with perihilar bile duct malignancy. J Gastrointest Surg. 2020;24(7):1630-8. 
34 Jo JH, Chung MJ, Han DH, Park JY, Bang S, Park SW, et al. Best options for preoperative biliary drainage in patients with Klatskin tumors. Surg Endosc. 2017;31(1):422-9.

35 DeOliveira ML, Cunningham SC, Cameron JL, Kamangar F, Winter JM, Lillemoe KD, et al. Cholangiocarcinoma: thirty-one-year experience with 564 patients at a single institution. Ann Surg. 2007;245(5):755-62.

36 Thomas MN, Weninger E, Angele M, Bösch F, Pratschke S, Andrassy J, et al. Intraoperative simulation of remnant liver function during anatomic liver resection with indocyanine green clearance (LiMON) measurements. HPB. 2015;17(6):471-6.

37 Stockmann M, Lock JF, Riecke B, Heyne K, Martus P, Fricke M, et al. Prediction of postoperative outcome after hepatectomy with a new bedside test for maximal liver function capacity. Ann Surg. 2009;250(1):119-25.

38 Baili E, Tsilimigras DI, Moris D, Sahara K, Pawlik TM. Technical modifications and outcomes after associating liver partition and portal vein ligation for staged hepatectomy (ALPPS) for primary liver malignancies: a systematic review. Surg Oncol. 2020;33:7080.

39 D'Haese JG, Neumann J, Weniger M Pratschke S, Björnsson B, Ardiles V, et al. Should ALPPS be used for liver resection in intermediate-stage HCC? Ann Surg Oncol. 2016;23(4):1335-43.

40 Bösch F, Ilhan H, Pfahler V, Thomas M, Knösel T, Eibl V, et al. Radioembolization for neuroendocrine liver metastases is safe and effective prior to major hepatic resection. Hepatobiliary Surg Nutr. 2020;9(3):312-21.

41 Schnitzbauer AA, Lang SA, Goessmann $\mathrm{H}$, Nadalin S, Baumgart J, Farkas SA, et al. Right portal vein ligation combined with in situ splitting induces rapid left lateral liver lobe hypertrophy enabling 2 -staged extended right hepatic resection in small-for-size settings. Ann Surg. 2012;255(3):405-14.

42 Isfordink CJ, Samim M, Braat MNGJA, Almalki AM, Hagendoorn J, Borel Rinkes IHM, et al. Portal vein ligation versus portal vein embolization for induction of hypertrophy of the future liver remnant: a systematic review and meta-analysis. Surg Oncol. 2017;26(3): 257-67.

43 van Lienden KP, van den Esschert JW, de Graaf W, Bipat S, Lameris JS, van Gulik TM, et al. Portal vein embolization before liver resection: a systematic review. Cardiovasc Intervent Radiol. 2013;36(1):25-34.

44 Guiu B, Chevallier P, Denys A, Delhom E, Pierredon-Foulongne MA, Rouanet $\mathrm{P}$, et al. Simultaneous trans-hepatic portal and hepatic vein embolization before major hepatectomy: the liver venous deprivation technique. Eur Radiol. 2016;26(12):4259-67.

45 Heil J, Schadde E. Simultaneous portal and hepatic vein embolization before major liver resection. Langenbecks Arch Surg. 2021; 406(5):1295-305.
46 Garlipp B, de Baere T, Damm R, Irmscher R, van Buskirk M, Stübs P, et al. Left-liver hypertrophy after therapeutic right-liver radioembolization is substantial but less than after portal vein embolization. Hepatology. 2014; 59(5):1864-73.

47 Vouche M, Lewandowski RJ, Atassi R, Memon K, Gates VL, Ryu RK, et al. Radiation lobectomy: time-dependent analysis of future liver remnant volume in unresectable liver cancer as a bridge to resection. J Hepatol. 2013;59(5):1029-36.

48 Wiggers JK, Groot Koerkamp B, Cieslak KP, Doussot A, van Klaveren D, Allen PJ, et al. Postoperative mortality after liver resection for perihilar cholangiocarcinoma: development of a risk score and importance of biliary drainage of the future liver remnant. J Am Coll Surg. 2016;223(2):321-31.e1.

49 Stavrou GA, Donati M, Faiss S, Jenner RM, Niehaus KJ, Oldhafer KJ. [Perihilar cholangiocarcinoma (Klatskin tumor)]. Chirurg. 2014;85(2):155-65; quiz 166-7.

50 Nuzzo G, Giuliante F, Ardito F, Giovannini I, Aldrighetti L, Belli G, et al. Improvement in perioperative and long-term outcome after surgical treatment of hilar cholangiocarcinoma: results of an Italian multicenter analysis of 440 patients. Arch Surg. 2012;147(1):26-34.

51 Filmann N, Walter D, Schadde E, Bruns C, Keck T, Lang H, et al. Mortality after liver surgery in Germany. Br J Surg. 2019;106(11): 1523-9.

$52 \mathrm{Wu}$ L, Tsilimigras DI, Paredes AZ, Mehta R, Hyer JM, Merath K, et al. Trends in the incidence, treatment and outcomes of patients with intrahepatic cholangiocarcinoma in the USA: facility type is associated with margin status, use of lymphadenectomy and overall survival. World J Surg. 2019;43(7):1777-87.

53 McMillan RR, Saharia A, Abdelrahim M, Ghobrial RM. New breakthroughs for liver transplantation of cholangiocarcinoma. Curr Transpl Rep. 2021;8(1):21-7.

54 Lunsford KE, Javle M, Heyne K, Shroff RT, Abdel-Wahab R, Gupta N, et al. Liver transplantation for locally advanced intrahepatic cholangiocarcinoma treated with neoadjuvant therapy: a prospective case-series. Lancet Gastroenterol Hepatol. 2018;3(5):337-48.

55 Darwish Murad S, Kim WR, Harnois DM, Douglas DD, Burton J, Kulik LM, et al. Efficacy of neoadjuvant chemoradiation, followed by liver transplantation, for perihilar cholangiocarcinoma at 12 US centers. Gastroenterology. 2012;143(1):88-98.e3; quiz e14.

56 Sapisochin G, Facciuto M, Rubbia-Brandt L, Marti J, Mehta N, Yao FY, et al. Liver transplantation for "very early" intrahepatic cholangiocarcinoma: international retrospective study supporting a prospective assessment. Hepatology. 2016;64(4):1178-88.

57 Acher AW, Weber SM, Pawlik TM. Liver transplantation for perihilar cholangiocarcinoma: patient selection and outcomes. Expert Rev Gastroenterol Hepatol. 2021;15(5):55566.
58 Bahra M, Langrehr JM, Neuhaus P. [Carcinomas of the distal bile duct]. Chirurg. 2006; 77(4):335-40.

59 Ohtsuka M, Ito $\mathrm{H}$, Kimura F, Shimizu H, Togawa A, Yoshidome H, et al. Results of surgical treatment for intrahepatic cholangiocarcinoma and clinicopathological factors influencing survival. Br J Surg. 2002;89(12):152531.

60 Wang Y, Li J, Xia Y, Gong R, Wang K, Yan Z, et al. Prognostic nomogram for intrahepatic cholangiocarcinoma after partial hepatectomy. J Clin Oncol. 2013;31(9):1188-95.

61 Spolverato G, Kim Y, Alexandrescu S, Marques HP, Lamelas J, Aldrighetti L, et al. Management and outcomes of patients with recurrent intrahepatic cholangiocarcinoma following previous curative-intent surgical resection. Ann Surg Oncol. 2016;23(1):23543.

62 Kitano Y, Yamashita YI, Nakagawa S, Okabe $\mathrm{H}$, Imai K, Chikamoto A, et al. Effectiveness of surgery for recurrent cholangiocarcinoma: a single center experience and brief literature review. Am J Surg. 2020;219(1):175-80.

63 Ebata T, Hirano S, Konishi M, Uesaka K, Tsuchiya Y, Ohtsuka M, et al. Randomized clinical trial of adjuvant gemcitabine chemotherapy versus observation in resected bile duct cancer. Br J Surg. 2018;105(3):192-202.

64 Edeline J, Benabdelghani M, Bertaut A, Watelet J, Hammel P, Joly JP, et al. Gemcitabine and oxaliplatin chemotherapy or surveillance in resected biliary tract cancer (PRODIGE 12-ACCORD 18-UNICANCER GI): a randomized phase III study. J Clin Oncol. 2019; 37(8):658-67.

65 Primrose JN, Fox RP, Palmer DH, Malik HZ Prasad R, Mirza D, et al. Capecitabine compared with observation in resected biliary tract cancer (BILCAP): a randomised, controlled, multicentre, phase 3 study. Lancet Oncol. 2019;20(5):663-73.

66 Shroff RT, Kennedy EB, Bachini M, BekaiiSaab T, Crane C, Edeline J, et al. Adjuvant therapy for resected biliary tract cancer: ASCO clinical practice guideline. J Clin Oncol. 2019;37(12):1015-27.

67 Stein A, Arnold D, Bridgewater J, Goldstein D, Jensen LH, Klümpen HJ, et al. Adjuvant chemotherapy with gemcitabine and cisplatin compared to observation after curative intent resection of cholangiocarcinoma and muscle invasive gallbladder carcinoma (ACTICCA-1 trial) - a randomized, multidisciplinary, multinational phase III trial. BMC Cancer. 2015; 15:564.

68 Nakachi K, Konishi M, Ikeda M, Mizusawa J, Eba J, Okusaka T, et al. A randomized phase III trial of adjuvant S-1 therapy vs. observation alone in resected biliary tract cancer: Japan Clinical Oncology Group Study (JCOG1202, ASCOT). Jpn J Clin Oncol. 2018; 48(4):392-5. 
69 Ben-Josef E, Guthrie KA, El-Khoueiry AB, Corless CL, Zalupski MM, Lowy AM, et al. SWOG S0809: a phase II intergroup trial of adjuvant capecitabine and gemcitabine followed by radiotherapy and concurrent capecitabine in extrahepatic cholangiocarcinoma and gallbladder carcinoma. J Clin Oncol. 2015;33(24):2617-22.

70 Goetze TO, Bechstein WO, Bankstahl US, Keck T, Königsrainer A, Lang SA, et al. Neoadjuvant chemotherapy with gemcitabine plus cisplatin followed by radical liver resection versus immediate radical liver resection alone with or without adjuvant chemotherapy in incidentally detected gallbladder carcinoma after simple cholecystectomy or in front of radical resection of BTC (ICC/ECC) - a phase III study of the German registry of incidental gallbladder carcinoma platform (GR) - the AIO/CALGP/ACO - GAIN-trial. BMC Cancer. 2020;20(1):122.

71 Seidensticker R, Seidensticker M, Doegen K, Mohnike K, Schütte K, Stübs P, et al. Extensive use of interventional therapies improves survival in unresectable or recurrent intrahepatic cholangiocarcinoma. Gastroenterol Res Pract. 2016;2016:8732521.

72 Lencioni R, Crocetti L, Cioni D, Della Pina C, Bartolozzi C. Percutaneous radiofrequency ablation of hepatic colorectal metastases: technique, indications, results, and new promises. Invest Radiol. 2004;39(11):689-97.

$73 \mathrm{Kim} \mathrm{JH}$, Won HJ, Shin YM, Kim KA, Kim PN. Radiofrequency ablation for the treatment of primary intrahepatic cholangiocarcinoma. AJR Am J Roentgenol. 2011;196(2):W205-9.

74 Mahnken AH, Bruners P, Günther RW. Techniques of interventional tumor therapy. Dtsch Arztebl Int. 2008;105(38):646-53.

75 Ricke J, Wust P, Stohlmann A, Beck A, Cho $\mathrm{CH}$, Pech $\mathrm{M}$, et al. CT-guided interstitial brachytherapy of liver malignancies alone or in combination with thermal ablation: phase I-II results of a novel technique. Int J Radiat Oncol Biol Phys. 2004;58(5):1496-505.

76 Rühl R, Ricke J. Image-guided micro-therapy for tumor ablation: from thermal coagulation to advanced irradiation techniques. Onkologie. 2006;29(5):219-24.

77 Schnapauff D, Denecke T, Grieser C, Collettini F, Colletini F, Seehofer D, et al. Computed tomography-guided interstitial HDR brachytherapy (CT-HDRBT) of the liver in patients with irresectable intrahepatic cholangiocarcinoma. Cardiovasc Intervent Radiol. 2012; 35(3):581-7.

78 Wieners G, Pech M, Hildebrandt B, Peters N, Nicolaou A, Mohnike K, et al. Phase II feasibility study on the combination of two different regional treatment approaches in patients with colorectal "liver-only" metastases: hepatic interstitial brachytherapy plus regional chemotherapy. Cardiovasc Intervent Radiol. 2009;32(5):937-45.
79 Jonczyk M, Collettini F, Schnapauff D, Geisel D, Boning G, Feldhaus F, et al. Cholangiocarcinoma: CT-guided high-dose rate brachytherapy (CT-HDRBT) for limited $(<4 \mathrm{~cm})$ and large $(>4 \mathrm{~cm})$ tumors. Anticancer Res. 2018:38(10):5843-52.

80 Mohnike K, Wieners G, Schwartz F, Seidensticker M, Pech M, Ruehl R, et al. Computed tomography-guided high-dose-rate brachytherapy in hepatocellular carcinoma: safety, efficacy, and effect on survival. Int J Radiat Oncol Biol Phys. 2010;78(1):172-9.

81 Kamphues C, Seehofer D, Collettini F, Bahra M, Neuhaus P, Wust P, et al. Preliminary experience with CT-guided high-dose rate brachytherapy as an alternative treatment for hepatic recurrence of cholangiocarcinoma. HPB. 2012;14(12):791-7.

82 Mosconi C, Cappelli A, Ascanio S, Pettinari I, Modestino F, Renzulli M, et al. Yttrium-90 microsphere radioembolization in unresectable intrahepatic cholangiocarcinoma. Future Oncol. 2017;13(15):1301-10.

83 Park SY, Kim JH, Yoon HJ, Lee IS, Yoon HK, Kim KP. Transarterial chemoembolization versus supportive therapy in the palliative treatment of unresectable intrahepatic cholangiocarcinoma. Clin Radiol. 2011;66(4): 322-8.

84 Saxena A, Bester L, Chua TC, Chu FC, Morris DL. Yttrium-90 radiotherapy for unresectable intrahepatic cholangiocarcinoma: a preliminary assessment of this novel treatment option. Ann Surg Oncol. 2010;17(2):484-91.

85 Aliberti C, Benea G, Tilli M, Fiorentini G. Chemoembolization (TACE) of unresectable intrahepatic cholangiocarcinoma with slowrelease doxorubicin-eluting beads: preliminary results. Cardiovasc Intervent Radiol. 2008;31(5):883-8.

86 Burger I, Hong K, Schulick R, Georgiades C, Thuluvath $\mathrm{P}$, Choti M, et al. Transcatheter arterial chemoembolization in unresectable cholangiocarcinoma: initial experience in a single institution. J Vasc Interv Radiol. 2005; 16(3):353-61.

87 Herber S, Otto G, Schneider J, Manzl N, Kummer I, Kanzler S, et al. Transarterial chemoembolization (TACE) for inoperable intrahepatic cholangiocarcinoma. Cardiovasc Intervent Radiol. 2007;30(6):1156-65.

88 Kiefer MV, Albert M, McNally M, Robertson M, Sun W, Fraker D, et al. Chemoembolization of intrahepatic cholangiocarcinoma with cisplatinum, doxorubicin, mitomycin C, ethiodol, and polyvinyl alcohol: a 2-center study. Cancer. 2011;117(7):1498-505.

89 Kim JH, Yoon HK, Sung KB, Ko GY, Gwon DI, Shin JH, et al. Transcatheter arterial chemoembolization or chemoinfusion for unresectable intrahepatic cholangiocarcinoma: clinical efficacy and factors influencing outcomes. Cancer. 2008;113(7):1614-22.
90 Kuhlmann JB, Euringer W, Spangenberg HC, Breidert M, Blum HE, Harder J, et al. Treatment of unresectable cholangiocarcinoma: conventional transarterial chemoembolization compared with drug eluting bead-transarterial chemoembolization and systemic chemotherapy. Eur J Gastroenterol Hepatol. 2012;24(4):437-43.

91 Schiffman SC, Metzger T, Dubel G, Andrasina T, Kralj I, Tatum C, et al. Precision hepatic arterial irinotecan therapy in the treatment of unresectable intrahepatic cholangiocellular carcinoma: optimal tolerance and prolonged overall survival. Ann Surg Oncol. 2011;18(2): 431-8.

92 Vogl TJ, Naguib NN, Nour-Eldin NE, Bechstein WO, Zeuzem S, Trojan J, et al. Transarterial chemoembolization in the treatment of patients with unresectable cholangiocarcinoma: results and prognostic factors governing treatment success. Int J Cancer. 2012;131(3):733-40.

93 Seidensticker R, Ricke J, Seidensticker M. Integration of chemoembolization and radioembolization into multimodal treatment of cholangiocarcinoma. Best Pract Res Clin Gastroenterol. 2015;29(2):319-32.

94 Camacho JC, Kokabi N, Xing M, Prajapati HJ, El-Rayes B, Kim HS. Modified response evaluation criteria in solid tumors and European Association for the study of the liver criteria using delayed-phase imaging at an early time point predict survival in patients with unresectable intrahepatic cholangiocarcinoma following yttrium-90 radioembolization. J Vasc Interv Radiol. 2014;25(2):256-65.

95 Filippi L, Pelle G, Cianni R, Scopinaro F, Bagni O. Change in total lesion glycolysis and clinical outcome after $Y$ radioembolization in intrahepatic cholangiocarcinoma. Nucl Med Biol. 2015;42(1):59-64.

96 Haug AR, Heinemann V, Bruns CJ, Hoffmann R, Jakobs T, Bartenstein P, et al. $18 \mathrm{~F}$ FDG PET independently predicts survival in patients with cholangiocellular carcinoma treated with $90 \mathrm{Y}$ microspheres. Eur J Nucl Med Mol Imaging. 2011;38(6):1037-45.

97 Hoffmann RT, Paprottka PM, Schön A, Bamberg F, Haug A, Dürr EM, et al. Transarterial hepatic yttrium-90 radioembolization in patients with unresectable intrahepatic cholangiocarcinoma: factors associated with prolonged survival. Cardiovasc Intervent Radiol. 2012;35(1):105-16.

98 Ibrahim SM, Mulcahy MF, Lewandowski RJ, Sato KT, Ryu RK, Masterson EJ, et al. Treatment of unresectable cholangiocarcinoma using yttrium-90 microspheres: results from a pilot study. Cancer. 2008;113(8):2119-28.

99 Mouli S, Memon K, Baker T, Benson AB 3rd, Mulcahy MF, Gupta R, et al. Yttrium-90 radioembolization for intrahepatic cholangiocarcinoma: safety, response, and survival analysis. J Vasc Interv Radiol. 2013;24(8): 1227-34. 
100 Rafi S, Piduru SM, El-Rayes B, Kauh JS, Kooby DA, Sarmiento JM, et al. Yttrium-90 radioembolization for unresectable standardchemorefractory intrahepatic cholangiocarcinoma: survival, efficacy, and safety study. Cardiovasc Intervent Radiol. 2013;36(2): $440-8$.

101 Soydal C, Kucuk ON, Bilgic S, Ibis E. Radioembolization with (90)Y resin microspheres for intrahepatic cholangiocellular carcinoma: prognostic factors. Ann Nucl Med. 2016;30(1):29-34.

102 Shaker TM, Chung C, Varma MK, Doherty MG, Wolf AM, Chung MH, et al. Is there a role for Ytrrium-90 in the treatment of unresectable and metastatic intrahepatic cholangiocarcinoma? Am J Surg. 2018;215(3): 467-70.

103 Zhen Y, Liu B, Chang Z, Ren H, Liu Z, Zheng J. A pooled analysis of transarterial radioembolization with yttrium-90 microspheres for the treatment of unresectable intrahepatic cholangiocarcinoma. Onco Targets Ther. 2019;12:4489-98.

104 Valle J, Wasan H, Palmer DH, Cunningham D, Anthoney A, Maraveyas A, et al. Cisplatin plus gemcitabine versus gemcitabine for biliary tract cancer. N Engl J Med. 2010; 362(14):1273-81.

105 Lamarca A, Ross P, Wasan HS, Hubner RA, McNamara MG, Lopes A, et al. Advanced intrahepatic cholangiocarcinoma: post hoc analysis of the $\mathrm{ABC}-01,-02$, and -03 clinical trials. J Natl Cancer Inst. 2020;112(2):20010.

106 Edeline J, Touchefeu Y, Guiu B, Farge O, Tougeron D, Baumgaertner I, et al. Radioembolization plus chemotherapy for firstline treatment of locally advanced intrahepatic cholangiocarcinoma: a phase 2 clinical trial. JAMA Oncol. 2019;6(1):51-9.

107 Bargellini I, Mosconi C, Pizzi G, Lorenzoni G, Vivaldi C, Cappelli A, et al. Yttrium-90 radioembolization in unresectable intrahepatic cholangiocarcinoma: results of a multicenter retrospective study. Cardiovasc Intervent Radiol. 2020;43(9):1305-14.

108 Boehm LM, Jayakrishnan TT, Miura JT, Zacharias AJ, Johnston FM, Turaga KK, et al. Comparative effectiveness of hepatic artery based therapies for unresectable intrahepatic cholangiocarcinoma. J Surg Oncol. 2015;111(2):213-20.

109 Rayar M, Levi Sandri GB, Houssel-Debry P, Camus C, Sulpice L, Boudjema K. Multimodal therapy including yttrium-90 radioembolization as a bridging therapy to liver transplantation for a huge and locally advanced intrahepatic cholangiocarcinoma. J Gastrointestin Liver Dis. 2016;25(3):401-4.

110 Zoepf T, Jakobs R, Arnold JC, Apel D, Riemann JF. Palliation of nonresectable bile duct cancer: improved survival after photodynamic therapy. Am J Gastroenterol. 2005; 100(11):2426-30.
111 Ortner ME, Caca K, Berr F, Liebetruth J, Mansmann U, Huster D, et al. Successful photodynamic therapy for nonresectable cholangiocarcinoma: a randomized prospective study. Gastroenterology. 2003; 125(5):1355-63.

112 Lu Y, Liu L, Wu JC, Bie LK, Gong B. Efficacy and safety of photodynamic therapy for unresectable cholangiocarcinoma: a metaanalysis. Clin Res Hepatol Gastroenterol. 2015;39(6):718-24.

113 Pereira SP, Jitlal M, Duggan M, Lawrie E, Beare S, O'Donoghue $\mathrm{P}$, et al. PHOTOSTENT-02: porfimer sodium photodynamic therapy plus stenting versus stenting alone in patients with locally advanced or metastatic biliary tract cancer. ESMO Open. 2018;3(5):e000379.

114 Sofi AA, Khan MA, Das A, Sachdev M, Khuder S, Nawras A, et al. Radiofrequency ablation combined with biliary stent placement versus stent placement alone for malignant biliary strictures: a systematic review and meta-analysis. Gastrointest Endosc. 2018;87(4):944-51.e1.

115 Yang J, Wang J, Zhou H, Zhou Y, Wang Y, Jin $\mathrm{H}$, et al. Efficacy and safety of endoscopic radiofrequency ablation for unresectable extrahepatic cholangiocarcinoma: a randomized trial. Endoscopy. 2018;50(8):75160.

116 Gao DJ, Yang JF, Ma SR, Wu J, Wang TT, Jin $\mathrm{HB}$, et al. Endoscopic radiofrequency ablation plus plastic stent placement versus stent placement alone for unresectable extrahepatic biliary cancer: a multicenter randomized controlled trial. Gastrointest Endosc. 2021;94(1):91-100.e2.

117 Yang J, Wang J, Zhou H, Wang Y, Huang H, Jin $\mathrm{H}$, et al. Endoscopic radiofrequency ablation plus a novel oral 5-fluorouracil compound versus radiofrequency ablation alone for unresectable extrahepatic cholangiocarcinoma. Gastrointest Endosc. 2020;92(6): 1204-12.e1.

118 Okusaka T, Nakachi K, Fukutomi A, Mizuno N, Ohkawa S, Funakoshi A, et al. Gemcitabine alone or in combination with cisplatin in patients with biliary tract cancer: a comparative multicentre study in Japan. $\mathrm{Br}$ J Cancer. 2010;103(4):469-74.

119 Valle J, Wasan H, Palmer DH, Cunningham D, Anthoney A, Maraveyas A, et al. Cisplatin plus gemcitabine versus gemcitabine for biliary tract cancer. N Engl J Med. 2010; 362(14):1273-81.

120 Lamarca A, Benafif S, Ross P, Bridgewater J, Valle JW. Cisplatin and gemcitabine in patients with advanced biliary tract cancer $(\mathrm{ABC})$ and persistent jaundice despite optimal stenting: effective intervention in patients with luminal disease. Eur J Cancer. 2015;51(13):1694-703.
121 Lamarca A, Palmer DH, Wasan HS, Ross PJ, Ma YT, Arora A, et al. Second-line FOLFOX chemotherapy versus active symptom control for advanced biliary tract cancer (ABC06): a phase 3 , open-label, randomised, controlled trial. Lancet Oncol. 2021;22(5):690701.

122 Shroff RT, Javle MM, Xiao L, Kaseb AO, Varadhachary GR, Wolff RA, et al. Gemcitabine, cisplatin, and nab-paclitaxel for the treatment of advanced biliary tract cancers: a phase 2 clinical trial. JAMA Oncol. 2019; 5(6):824-30.

123 Blagden SP, Rizzuto I, Suppiah P, O'Shea D, Patel M, Spiers L, et al. Anti-tumour activity of a first-in-class agent NUC-1031 in patients with advanced cancer: results of a phase I study. Br J Cancer. 2018;119(7):81522 .

124 Conroy T, Desseigne F, Ychou M, Bouché O, Guimbaud R, Bécouarn Y, et al. FOLFIRINOX versus gemcitabine for metastatic pancreatic cancer. N Engl J Med. 2011;364(19): 1817-25.

125 Phelip JM, Desrame J, Edeline J, Barbier E, Terrebonne E, Michel P, et al. 52P modified FOLFIRINOX versus CISGEM as first-line chemotherapy for advanced biliary tract cancer: results of AMEBICA PRODIGE 38 randomized phase II trial. Ann Oncol. 2020; 31:S260-1.

126 Ong CK, Subimerb C, Pairojkul C, Wongkham S, Cutcutache I, Yu W, et al. Exome sequencing of liver fluke-associated cholangiocarcinoma. Nat Genet. 2012;44(6):690-3

127 Jiao Y, Pawlik TM, Anders RA, Selaru FM, Streppel MM, Lucas DJ, et al. Exome sequencing identifies frequent inactivating mutations in BAP1, ARID1A and PBRM1 in intrahepatic cholangiocarcinomas. Nat Genet. 2013;45(12):1470-3.

128 Javle M, Bekaii-Saab T, Jain A, Wang Y, Kelley RK, Wang K, et al. Biliary cancer: utility of next-generation sequencing for clinical management. Cancer. 2016;122(24):383847.

129 Jusakul A, Cutcutache I, Yong CH, Lim JQ, Huang MN, Padmanabhan N, et al. Wholegenome and epigenomic landscapes of etiologically distinct subtypes of cholangiocarcinoma. Cancer Discov. 2017;7(10):1116-35.

130 Harding JJ, Lowery MA, Shih AH, Schvartzman JM, Hou S, Famulare C, et al. Isoform switching as a mechanism of acquired resistance to mutant isocitrate dehydrogenase in hibition. Cancer Discov. 2018;8(12):1540.

131 Lamarca A, Barriuso J, McNamara MG, Valle JW. Molecular targeted therapies: ready for "prime time" in biliary tract cancer. Hepatol. 2020;73(1):170-85.

132 Arai Y, Totoki Y, Hosoda F, Shirota T, Hama $\mathrm{N}$, Nakamura $\mathrm{H}$, et al. Fibroblast growth factor receptor 2 tyrosine kinase fusions define a unique molecular subtype of cholangiocarcinoma. Hepatology. 2014;59(4):1427-34. 
133 Kipp BR, Voss JS, Kerr SE, Barr Fritcher EG, Graham RP, Zhang L, et al. Isocitrate dehydrogenase 1 and 2 mutations in cholangiocarcinoma. Hum Pathol. 2012;43(10):15528.

134 Jain A, Borad MJ, Kelley RK, Wang Y, Abdel-Wahab R, Meric-Bernstam F, et al. Cholangiocarcinoma with FGFR genetic aberrations: a unique clinical phenotype. JCO Precis Oncol. 2018;(2):1-12.

135 Javle MM, Roychowdhury S, Kelley RK, Sadeghi S, Macarulla T, Waldschmidt DT, et al. Final results from a phase II study of infigratinib (BGJ398), an FGFR-selective tyrosine kinase inhibitor, in patients with previously treated advanced cholangiocarcinoma harboring an FGFR2 gene fusion or rearrangement. J Clin Oncol. 2021;39(3_Suppl):265.

136 Abou-Alfa GK, Sahai V, Hollebecque A, Vaccaro G, Melisi D, Al-Rajabi R, et al. Pemigatinib for previously treated, locally advanced or metastatic cholangiocarcinoma: a multicentre, open-label, phase 2 study. Lancet Oncol. 2020;21(5):671-84.

137 Hoy SM. Pemigatinib: first approval. Drugs. 2020;80(9):923-9.

138 Mazzaferro V, El-Rayes BF, Droz Dit Busset M, Cotsoglou C, Harris WP, Damjanov N, et al. Derazantinib (ARQ 087) in advanced or inoperable FGFR2 gene fusion-positive intrahepatic cholangiocarcinoma. Br J Cancer. 2019;120(2):165-71.

139 Park JO, Feng Y-H, Chen Y-Y, Su W-C, Oh $\mathrm{D}-\mathrm{Y}$, Shen $\mathrm{L}$, et al. Updated results of a phase IIa study to evaluate the clinical efficacy and safety of erdafitinib in Asian advanced cholangiocarcinoma (CCA) patients with FGFR alterations. J Clin Oncol. 2019;37(15_Suppl):4117.

140 BridgeBio Pharma and affiliate QED therapeutics announce FDA acceptance of new drug application for infigratinib for the treatment of cholangiocarcinoma. Press release BridgeBio Pharma. 2020 Dec 1.

141 Abou-Alfa GK, Macarulla T, Javle MM, Kelley RK, Lubner SJ, Adeva J, et al. Ivosidenib in IDH1-mutant, chemotherapy-refractory cholangiocarcinoma (ClarIDHy): a multicentre, randomised, double-blind, placebocontrolled, phase 3 study. Lancet Oncol. 2020;21(6):796-807.

142 Zhu AX, Macarulla T, Javle MM, Kelley RK, Lubner SJ, Adeva J, et al. Final results from ClarIDHy, a global, phase III, randomized, double-blind study of ivosidenib (IVO) versus placebo $(\mathrm{PBO})$ in patients (pts) with previously treated cholangiocarcinoma (CCA) and an isocitrate dehydrogenase 1 (IDH1) mutation. J Clin Oncol. 2021;39(3_Suppl): 266.

143 FDA. FDA approves ivosidenib for advanced or metastatic cholangiocarcinoma. 2021.
144 Galdy S, Lamarca A, McNamara MG, Hubner RA, Cella CA, Fazio N, et al. HER2/ HER3 pathway in biliary tract malignancies; systematic review and meta-analysis: a potential therapeutic target? Cancer Metastasis Rev. 2017;36(1):141-57.

145 Lee J, Park SH, Chang HM, Kim JS, Choi HJ, Lee MA, et al. Gemcitabine and oxaliplatin with or without erlotinib in advanced biliary-tract cancer: a multicentre, open-label, randomised, phase 3 study. Lancet Oncol. 2012;13(2):181-8.

146 Malka D, Cervera P, Foulon S, Trarbach T, de la Fouchardière C, Boucher E, et al. Gemcitabine and oxaliplatin with or without cetuximab in advanced biliary-tract cancer (BINGO): a randomised, open-label, noncomparative phase 2 trial. Lancet Oncol. 2014;15(8):819-28.

147 Peck J, Wei L, Zalupski M, O'Neil B, Villalona Calero M, Bekaii-Saab T. HER2/neu may not be an interesting target in biliary cancers: results of an early phase II study with lapatinib. Oncology. 2012;82(3):175-9.

148 Ramanathan RK, Belani CP, Singh DA, Tanaka M, Lenz HJ, Yen Y, et al. A phase II study of lapatinib in patients with advanced biliary tree and hepatocellular cancer. Cancer Chemother Pharmacol. 2009;64(4):77783.

149 Leone F, Marino D, Cereda S, Filippi R, Belli C, Spadi R, et al. Panitumumab in combination with gemcitabine and oxaliplatin does not prolong survival in wild-type KRAS advanced biliary tract cancer: a randomized phase 2 trial (Vecti-BIL study). Cancer. 2016;122(4):574-81.

150 Rizzo A, Ricci AD, Bonucci C, Tober N, Palloni A, Frega G, et al. Experimental HER2targeted therapies for biliary tract cancer. Expert Opin Investig Drugs. 2021;30(4): 389-99.

151 Meric-Bernstam F, Hanna DL, El-Khoueiry AB, Kang Y-K, Oh D-Y, Chaves JM, et al. Zanidatamab (ZW25) in HER2-positive biliary tract cancers (BTCs): results from a phase I study. J Clin Oncol. 2021;39(3 Suppl):299.

152 Goeppert B, Frauenschuh L, Renner M, Roessler S, Stenzinger A, Klauschen F, et al. BRAF V600E-specific immunohistochemistry reveals low mutation rates in biliary tract cancer and restriction to intrahepatic cholangiocarcinoma. Mod Pathol. 2014;27(7): 1028-34.

153 Drilon A, Laetsch TW, Kummar S, DuBois SG, Lassen UN, Demetri GD, et al. Efficacy of larotrectinib in TRK fusion-positive cancers in adults and children. $\mathrm{N}$ Engl J Med. 2018;378(8):731-9.

154 Doebele RC, Drilon A, Paz-Ares L, Siena S, Shaw AT, Farago AF, et al. Entrectinib in patients with advanced or metastatic NTRK fusion-positive solid tumours: integrated analysis of three phase 1-2 trials. Lancet Oncol. 2020;21(2):271-82.
155 Subbiah V, Lassen U, Élez E, Italiano A, Curigliano G, Javle M, et al. Dabrafenib plus trametinib in patients with $<\mathrm{em}>\mathrm{BRAF}<$ / em $>$ V600E-mutated biliary tract cancer (ROAR): a phase 2, open-label, single-arm, multicentre basket trial. Lancet Oncol. 2020; 21(9):1234-43.

156 Sharma P, Allison JP. The future of immune checkpoint therapy. Science. 2015 348(6230):56.

157 Loeuillard E, Conboy CB, Gores GJ, Rizvi S Immunobiology of cholangiocarcinoma. JHEP Rep. 2019;1(4):297-311.

158 Bonneville R, Krook MA, Kautto EA, Miya J, Wing MR, Chen HZ, et al. Landscape of microsatellite instability across 39 cancer types. JCO Precis Oncol. 2017;2017(1):1-15.

159 Le DT, Durham JN, Smith KN, Wang H, Bartlett BR, Aulakh LK, et al. Mismatch repair deficiency predicts response of solid tumors to PD-1 blockade. Science. 2017; 357(6349):409-13.

160 Javle MM, Murugesan K, Shroff RT, Borad MJ, Abdel-Wahab R, Schrock AB, et al. Profiling of 3,634 cholangiocarcinomas (CCA) to identify genomic alterations (GA), tumor mutational burden (TMB), and genomic loss of heterozygosity (gLOH). J Clin Oncol. 2019;37(15 Suppl):4087.

161 Jain A, Shroff RT, Zuo M, Weatherly J, Meric-Bernstam F, Isaacs R, et al. Tumor mutational burden (TMB) and co-existing actionable mutations in biliary tract cancers (BTC). J Clin Oncol. 2017;35(15 Suppl): 4086.

162 Piha-Paul SA, Oh DY, Ueno M, Malka D, Chung HC, Nagrial A, et al. Efficacy and safety of pembrolizumab for the treatment of advanced biliary cancer: results from the KEYNOTE-158 and KEYNOTE-028 studies. Int J Cancer. 2020;147(8):2190-8.

163 Ueno M, Ikeda M, Morizane C, Kobayashi S, Ohno I, Kondo S, et al. Nivolumab alone or in combination with cisplatin plus gemcitabine in Japanese patients with unresectable or recurrent biliary tract cancer: a nonrandomised, multicentre, open-label, phase 1 study. Lancet Gastroenterol Hepatol. 2019; 4(8):611-21.

164 Ioka T, Ueno M, Oh D-Y, Fujiwara Y, Chen J-S, Doki Y, et al. Evaluation of safety and tolerability of durvalumab (D) with or without tremelimumab ( $\mathrm{T}$ ) in patients (pts) with biliary tract cancer (BTC). J Clin Oncol. 2019;37(4_Suppl):387.

165 Marabelle A, Le DT, Ascierto PA, Di Giacomo AM, De Jesus-Acosta A, Delord JP, et al. Efficacy of pembrolizumab in patients with noncolorectal high microsatellite instability/mismatch repair-deficient cancer: results from the phase II KEYNOTE-158 study. J Clin Oncol. 2020;38(1):1-10. 
166 Klein O, Kee D, Nagrial A, Markman B, Underhill C, Michael M, et al. Evaluation of combination nivolumab and ipilimumab immunotherapy in patients with advanced biliary tract cancers: subgroup analysis of a phase 2 nonrandomized clinical trial. JAMA Oncol. 2020;6(9):1405-9.

167 Lin J, Yang X, Long J, Zhao S, Mao J, Wang $\mathrm{D}$, et al. Pembrolizumab combined with lenvatinib as non-first-line therapy in patients with refractory biliary tract carcinoma. Hepatobiliary Surg Nutr. 2020;9(4):414-24.
168 Villanueva L, Lwin Z, Chung HC, GomezRoca C, Longo F, Yanez E, et al. Lenvatinib plus pembrolizumab for patients with previously treated biliary tract cancers in the multicohort phase II LEAP-005 study. J Clin Oncol. 2021;39(3 Suppl):321.

169 Kelley RK, Mitchell E, Behr S, Hwang J, Keenan B, Cheung A, et al. Phase II trial of pembrolizumab (PEM) plus granulocyte macrophage colony stimulating factor (GM$\mathrm{CSF}$ ) in advanced biliary cancers (ABC). J Clin Oncol. 2018;36(4 Suppl):386.
170 Boilève A, Hilmi M, Gougis P, Cohen R Rousseau B, Blanc JF, et al. Triplet combination of durvalumab, tremelimumab, and paclitaxel in biliary tract carcinomas: safety run-in results of the randomized IMMUNOBIL PRODIGE 57 phase II trial. Eur J Cancer. 2021;143:55-63. 